\title{
LAPAROSCOPIC MANAGEMENT OF BENIGN ADNEXAL MASSES
}

\section{Dr. Vinita Sarbhai}

Dr Medha Yadav*
Associate professor, Department of Obstetrics and Gynaecology, Kasturba Hospital, Daryaganj, New Delhi - 110002.

Post Graduate student, Department of Obstetrics and Gynaecology, Kasturba Hospital, Daryaganj, New Delhi- $110002 .{ }^{*}$ Corresponding Author

ABSTRACT Objective: to assess the effectiveness of laparoscopic management of adnexal masses suspected to be benign on pre-operative evaluation. Material And Method: all women with 2018 to December 2018 were included in the study. Results: 32 women with adnexal mass presumed to be benign were taken up for laparoscopy. Diagnosis in $34.4 \%$ cases was endometriosis, $25 \%$ simple ovarian cyst, $12.5 \%$ hydroslapinx, $9.4 \%$ dermoid cyst, $6.3 \%$ paraovarian cyst, $3.1 \%$ tubo-ovarian abscess, $3.1 \%$ TO mass, $3.1 \%$ tubal ectopic pregnancy and $3.1 \%$ PCOS. Most commonly performed surgery was cystectomy (53.1\% cases). Other procedures included deroofing and fulguration( $15.6 \%$ ), cuff salpingostomy (12.5\%), aspiration (6.3\%), salpingectomy (3.1\%), salpingo-oopherectomy $(3.1 \%)$ and ovariectomy $(3.1 \%)$. Conclusions: laparoscopy is safe procedure and can be used in managing patients with benign adnexal masses. Proper selection of cases is important and can be achieved by ultrasonography, CA-125, CT scan and MRI.

KEYWORDS : benign adnexal mass, laparoscopy

\section{INTRODUCTION}

Adnexal masses are one of the most common pathologies among women of all age groups. It has been estimated that $5 \%$ to $10 \%$ of women will undergo a surgical procedure owing to a suspected ovarian mass during their lifetime, and $13 \%$ of these women will suffer from malignancy. ${ }^{[1]}$ The primary aim in management of ovarian mass is to rule out malignancy, more so in pre-pubertal and postmenopausal women and then to remove the mass without any complications. With recent advances in operative laparoscopy and proper preoperative evaluation, management of the benign adnexal mass with this method offers the potential for safe and effective minimally invasive surgery.

\section{MATERIAL AND METHODS}

This prospective study was conducted in Kasturba hospital from January 2018 to December 2018. 32 women with adnexal mass, presumed to be benign, were included in the study. Preoperative evaluation included detailed history, examination, routine blood investigations for preanaesthetic checkup and ultrasonography with Doppler study to check vascularity. In few women, where malignancy was suspected, CA-125, MRI or CT scan were performed to rule out malignancy. $\beta$-HCG was performed in women with ectopic pregnancy.

\section{INCLUSION CRITERIA}

Non pregnant women, more than 18years, with persistent adnexal mass suspected to be benign on clinical features and ultrasound.

\section{EXCLUSION CRITERIA:}

1) Adnexal mass with suspicion of malignancy (Complex large, solid, fixed, mass with thick septations ( $>2 \mathrm{~mm}$ ), irregular borders, variable echogenecities, papillary projections, high volume, low vascular resistance and pulsatility on doppler ultrasound, ascites, matted bowel, family history of breast and ovarian cancer and CAl25>200units $/ \mathrm{ml}$ in premenopausal, and $>35$ units $/ \mathrm{ml}$ in post-menopausal age group).

2) Masses arising from urinary tract and gastrointestinal tract.

3) Contraindications of laparoscopy: Congestive heart failure, Intracranial hypertension, prior or suspected pneumothorax or emphysema. Acute infection of abdominal wall or pelvis.

All patients meeting inclusion criteria with no exclusion criteria were taken up for laparoscopy. Procedure was done under general anaesthesia in all patients. Peritoneal cavity was entered through palmar's point in patients where adhesions were suspected. All peritoneal surfaces , pelvis, pouch of douglas, diaphragm, paracolic gutters, omentum, bowel surfaces and lever were inspected and fluid for peritoneal cytology were obtained in indicated cases. Procedures included cystectomy, deroofing and fulguration, cuff salpingostomy, aspiration, salpingectomy, salpingooopherectomy, ovariectomy, adhesiolysis and ovarian drilling. Specimen retrieved was sent sent for histopathology.

\section{RESULTS}

Age of patients ranged from $20-40$ years with the mean of 28 years \pm standard deviation of 4.71 years and median of 28 years. All women were in reproductive group and there was no patient in post menopausal age group. Majority of the patients had BMI $<25$. Only 1 patient $(3.1 \%)$ had BMI $>25$. Most common presenting complaint was pain abdomen and infertility. Menstrual abnormality was presenting complaint in $28.1 \%$. Adnexal mass was diagnosed incidentally in $15.6 \%$ during $\mathrm{P} / \mathrm{V}$ examination or by further investigations in women who presented with other complains like discharge P/V. 2 cases $(6.3 \%)$ presented with lump in abdomen.

History of abdominal surgery was present in 5 cases (15.6\%). In 4 cases (12.5\%) LSCS was performed in past and 1 case (3.1\%) had abdominal hysterectomy in past. Out of all previous Caesarian sections, one patient had previous three LSCS. Size of mass ranged from 4 to $15 \mathrm{~cm}$ and 5 (15.6\%) cases had mass in the range of $\geq 10 \mathrm{~cm}$. Neither technical difficulty nor malignancy was encountered during removal of masses with size $\geq 10 \mathrm{~cm}$

Per operative diagnosis based on laparoscopic findings were endometrioma $(34.4 \%)$, simple ovarian cyst $(25 \%)$, hydrosalpinx (12.5\%), tubo ovarian abscess (3.1\%), tubo ovarian mass $(3.1 \%)$, dermoid cyst $(9.4 \%)$, para ovarian cyst (6.3\%), PCOS (3.1\%) and tubal ectopic pregnancy (3.1\%).

Table 1: Type Of Laparoscopic Operations For Adnexal Masses ( $\mathrm{N}=32$ )

\begin{tabular}{|l|l|l|}
\hline Operative procedure & Number & Percentage (\%) \\
\hline Cystectomy & 17 & 53.1 \\
\hline Deroofing and fulguration & 5 & 15.6 \\
\hline Cuff neo-salpingostomy & 4 & 12.5 \\
\hline Aspiration & 2 & 6.3 \\
\hline Salpingectomy & 1 & 3.1 \\
\hline Salpingo-Oopherectomy & 1 & 3.1 \\
\hline Ovariectomy & 1 & 3.1 \\
\hline
\end{tabular}




\begin{tabular}{|l|l|l|}
\hline Other procedure \\
\hline Adhesiolysis & 10 & 31.25 \\
\hline Ovarian drilling & 1 & 3.1 \\
\hline
\end{tabular}

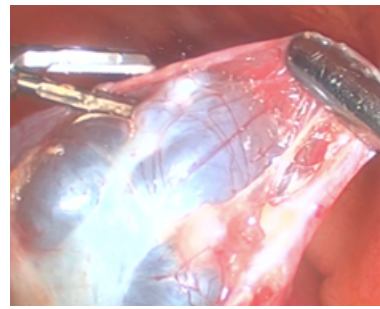

Figure No.1: Cystectomy Of Paraovarian Cyst

Most common surgery performed was cystectomy (17cases). Ovarian cystectomy is the method of choice in young patients to preserve fertility, as most of our patients are in reproductive age group and have presented as infertility(figure no.1). Small endometriomas, where cystectomy was not possible, were managed by deroofing and fulguration of base (5 cases)(figure no.2). Cuff neo-salpingostomy after drainage of fluid collection in the tube was done in all 4 cases of hydrosalpinx. Salpingectomy was done in l case for ruptured tubal ectopic pregnancy. Salpingo-Oopherectomy was performed in 1 case where ovary was twisted and cyst was suspected to be necrosed so infundibulopelvic ligament along with broad ligament that was attached to the tube was clamped, cut and sealed with the help of vessel sealing device. Ovariectomy was done in 1 case, where cyst wall was adherent to ovary and couldn't be separated so ovariectomy was decided. (Tablel).

\section{Table 2: Operative Statistics}

\begin{tabular}{|l|l|l|}
\hline & Mean & Median \\
\hline Blood loss(ml) & $85.94 \mathrm{ml} \pm 50.15 \mathrm{SD}$ & $80 \mathrm{ml}$ \\
\hline Operating Time & 75.44 minutes $\pm 27.88 \mathrm{SD}$ & 60 minutes \\
\hline $\begin{array}{l}\text { Duration of } \\
\text { hospital stay }\end{array}$ & 2.63 days $\pm 1.75 \mathrm{SD}$ & 2 days \\
\hline
\end{tabular}

The total blood loss ranged from 20 to $300 \mathrm{ml}$ with mean of $85.94 \mathrm{ml} \pm 50.15 \mathrm{SD}$. Blood loss of $>100 \mathrm{ml}$ was seen in case of ruptured ectopic pregnancy. The operating time ranged from 40 to 150 minutes with mean of $75.44 \mathrm{~min} \pm 27.88 \mathrm{SD}$. The most common reasons for prolongation of surgery were control of haemostasis, adhesiolysis, and extensive lavage in cases of spillage. (Table 2) No case was converted to laparotomy.

Table 3: Complications Of Laparoscopy In Study Subjects

\begin{tabular}{|l|l|l|}
\hline Complications & Number & Percentage (\%) \\
\hline Spillage of fluid & 21 & 65.6 \\
\hline Trocar site infections & 1 & 3.1 \\
\hline Uterine perforation & 1 & 3.1 \\
\hline $\begin{array}{l}\text { Re-appearance of cystic mass } \\
\text { (at follow up) }\end{array}$ & 1 & 3.1 \\
\hline
\end{tabular}

Spillage of fluid occurred in 21 cases (65.6\%) which were managed by irrigation. Other complications included trocar site infection in 1 case $(3.1 \%)$, uterine perforation in 1 case $(3.1 \%)$ and reappearance of mass in 1 case $(3.1 \%)$. Uterine perforation was sealed immediately and blood loss was within normal limits. (Table 3)

Trocar site infection was seen in 1 case which was managed by Intravenous antibiotics. One case which was initially diagnosed as genital TB by laparoscopy, and confirmed by CBNAAT, presented with reappearance of mass after 1 year. She was put on ATT for 9 months. Follow up scan, showed tubo-ovarian mass of size $9 * 10 \mathrm{~cm}$ for which she was offered second look laparoscopy but patient refused for surgery.

\section{DISCUSSION}

Adnexal masses are one of the commonest pathologies encountered in women in all age groups. These are on increasing trend with increase in obesity, infertility and lifestyle changes. The primary aim in management of ovarian mass is to rule out malignancy, more so in pre-pubertal and postmenopausal women and then to remove the mass without any complications.

Previously laparotomy was the only option for surgical management of these masses. Nowadays, laparoscopy has become the gold standard for management of adnexal masses. There are many fears associated with laparoscopy which include spillage related complications, encountering malignancy, upstaging of tumors and technical problems related with removal of large masses.

Eli Serur et $\alpha^{[2]}$, Ghezzi et al $^{[3]}$, and Kiran Aggarwal et $\alpha l^{[3]}$ in their study documented technical difficulty secondary to dense adhesion, malignancy and complications associated with trocar insertions like small bowel enterotomy as major reasons for conversion to laparotomy.

Grammatikakis et al $^{[5]}$ in their large series, on laparoscopic management of adnexal masses of 1552 women, reported conversion of laprotomy in $11.5 \%$ due to technical difficulties or suspicion of malignancy, while major complication occurred in very small number of patients $(0.6 \%)$ in the form of bowel or bladder injuries.

In our study both pre-pubertal and postmenopausal women were excluded from study and ultrasonography was used to rule out malignancy. In suspected cases help of other investigations like CA-125, CT scan and MRI was taken. No malignancy was encountered in our study. H. Matsushita ${ }^{[6]}$ reported that unexpected ovarian malignancy is rare $(1.5 \%)$ in carefully selected patients and presence of an early-stage unexpected ovarian malignancy did not alter the prognosis of the patients.

History of previous abdominal surgery was present in 5 cases including one patient with history of previous three LSCS and one with previous hysterectomy and in all these cases primary trocar was placed at palmer's point to avoid complication during trocar placement. No added technical difficulty was encountered in these cases.

Ghezzi et al ${ }^{[3]}$ concluded, from his study on 186 women with ovarian mass more than $10 \mathrm{~cm}$, that operating surgeon's experience, availability of frozen section, and adequate cancer surgery if indicated, are more important prognostic indicators than size.

From the present study and data from previous studies shows that most frequently occurring complications are fever, wound sepsis and bladder/ bowel injury. These can be avoided with proper patient selection, better aseptic precautions and taking extra precautions during primary trocar placement and adhesiolysis.

Other controversies associated with laparoscopy include spillage of cyst content, longer operating time and long learning curve. In present study spillage was seen in 21 cases and all these cases were managed by immediate copious lavage with normal saline. In study conducted by Victor Benezra et al ${ }^{[7]}$ spillage of dermoid contents was documented in $31.5 \%$ cases and none of the patient developed chemical perotinitis secondary to spillage. Spillage of mass contents should be avoided but fear of spillage shouldn't be used against choosing laparoscopy since these complications can be reduced by using immediately aspirating spilled contents and copious lavage with warm normal saline. 
the experience of surgeon and can be lesser when the surgeon is experienced with laparoscopy.

Advantages of laparoscopy over laparotomy like lesser blood loss, shorter hospital stay, early mobilization, less intraoperative and post-operative complications were confirmed in current study.

\section{CONCLUSION}

Our study confirms that laparoscopy can be safely performed for management of benign adnexal masses after proper selection of cases by using ultrasonography and markers like CA-125. We recommend operative laparoscopy as the gold standard for the surgical treatment of ovarian cysts. The procedure is associated with reduced operative blood loss, fewer postoperative complications, shorter hospitalization, less pain and earlier recovery compared with laparotomy.

Ethics Approval And Consent To Participate- The study was approved by institutional ethics committee. All procedures performed in studies involving human participants were in accordance with ethical standards of the institution.

\section{REFERENCES}

1. Pejovic T And Nezhat F. Laparoscopic Management of Adnexal Masses. Annals of the New York Academy of Sciences.2001; 943(1):255-268.

2. Serur E, Emeney P, Byrne D. JSLS. Laparoscopic Management of Adnexal Masses. 2001:5:143-151

3. Ghezzi F, Cromi A, Bergamini V, Uccella S, Siesto G, Franchi M. Should adnexal mass size influence surgical approach? A series of 186 laparoscopically managed large adnexal masses. BJOG An Int J Obstet Gynaecol. 2008; 115(8):1020-7.

4. Aggarwal K. Laparascopic Evaluation and Management of Benign Adnexal Masses. J Med Sci Clin Res. 2017;05(06):23024-30.

5. Grammatikakis I, Trompoukis P, Zervoudis S, Mavrelos C, Economides P, Tziortzioti V, et al. Laparoscopic Treatment of 1522 Adnexal Masses: An 8-Year Experience. Diagn Ther Endosc. 2015; 2015 (December 2013):1-3.

6. H. Matsushita, K. Watanabe, T. Yokoi, A. Wakatsuki, Unexpected ovarian malignancy following laparoscopic excision of adnexal masses, Human Reproduction, Volume 29, Issue 9, September 2014, Pages 1912-1917

7. Benezra V, Verma U, Whitted RW. Comparison of laparoscopy versus laparotomy for the surgical treatment of ovarian dermoid cysts. Gynecol Surg. 2005;2(2):89-92. 